\title{
Systemic immune-inflammation index independently predicts poor survival of older adults with hip fracture: a prospective cohort study
}

\author{
Zhi-Cong Wang ${ }^{\dagger}$, Wei Jiang ${ }^{\dagger}$, Xi Chen, Ling Yang, Hong Wang and Yue-Hong Liu*
}

\begin{abstract}
Background: The systemic immune-inflammation index (SII), based on peripheral platelet, neutrophil and lymphocyte counts, has been proven to be a promising prognostic indicator in various diseases. Hip fracture is a common injury among the older adults, and has become a global public health problem with high mortality and disability rates. However, the relationship between SII and the prognosis of hip fracture is not yet well-known. The aim of the this study was to explore the predictive value of SII in older adults with hip fracture undergoing surgery.

Methods: This was a prospective cohort study performed from January 2014 to December 2018 at a orthopaedic center, China. The SII was calculated as plateletXneutrophil/lymphocyte counts. Univariable and multivariable Cox proportional hazard models were used to assess the association between SII and all-cause mortality.

Results: A total of 290 older adults with hip fracture were included, and the mean (SD) age was 77.6 (8.6) years, and 189 (65.2\%) were female. The median (IQR) SII was $759.4(519.0-1128.7) \times 10^{9} / \mathrm{L}$. After a median follow-up time of 33.4 months, 13 (4.5\%), 26 (9.0\%) and 54 (18.6\%) patients died within the 30-day, 1-year and last follow-up, respectively. Multivariable Cox analysis revealed that each increase of 100 units of SII was associated with a $8 \%$ increased hazard of death at 1-year follow-up ( $\mathrm{HR}=1.08,95 \% \mathrm{Cl}: 1.01-1.17, p=0.033)$, and $9 \%$ increased hazard of death at last follow-up (HR=1.09, 95\% Cl: 1.03-1.15, $p=0.003)$.

Conclusions: SII is associated with poor all-cause mortality in older adults with hip fracture undergoing surgery, and deserves further investigation and application in clinical practice.
\end{abstract}

Keywords: Older adults, Hip fracture, Systemic immune-inflammation index, Prognosis, Mortality

\section{Background}

With the rapid development of the aging population, hip fracture has become more and more frequent in the older adults. Globally, an estimated 1.6 million hip fractures occurred in 2000 [1], and the number may rise to 2.6 million in 2025 and 4.5 million in 2050 [2]. Despite

\footnotetext{
* Correspondence: doctorliuyuehong@163.com

${ }^{\dagger}$ Zhi-Cong Wang and Wei Jiang contributed equally to this work. Orthopaedic Center of Deyang City, Department of Orthopedics, People's Hospital of Deyang City, Deyang City 618000, Sichuan, China
}

improvements in perioperative care, it is well known that hip fracture is associated with substantial excess mortality in older adults, and the mortality rates range between 1.0 and $7.2 \%$ at 30 days, and significantly increase to $23.5 \%$ within 1 year after hip fracture [3-7].

In order to predict the prognosis of hip fracture, many assessment tools have been developed, such as Nottingham Hip Fracture Score (NHFS) [8, 9], Physiologic and Operative Severity Score for the enUmeration of Mortality and Morbidity (POSSUM) [10, 11], and Almelo Hip

(c) The Author(s). 2021 Open Access This article is licensed under a Creative Commons Attribution 4.0 International License, which permits use, sharing, adaptation, distribution and reproduction in any medium or format, as long as you give appropriate credit to the original author(s) and the source, provide a link to the Creative Commons licence, and indicate if changes were made. The images or other third party material in this article are included in the article's Creative Commons licence, unless indicated otherwise in a credit line to the material. If material is not included in the article's Creative Commons licence and your intended use is not permitted by statutory regulation or exceeds the permitted use, you will need to obtain permission directly from the copyright holder. To view a copy of this licence, visit http://creativecommons.org/licenses/by/4.0/. The Creative Commons Public Domain Dedication waiver (http://creativecommons.org/publicdomain/zero/1.0/) applies to the data made available in this article, unless otherwise stated in a credit line to the data. 
Fracture Score (AHFS) [12]. However, none of the existing tools showed excellent discrimination or calibration $[11,13]$. Recently, some inflammatory markers, such as interleukin-6 (IL-6), C-reactive protein (CRP), prognostic nutritional index ratio (PNI), CRP/PNI ratio, and neutrophil-to-lymphocyte ratio (NLR) were found to be independently associated with increased early and longterm mortality after hip fracture [14-19].

The systemic immune-inflammation index (SII), which is a composite indicator integrating platelet, neutrophil and lymphocyte counts, has been proven to be a promising prognostic predictor in various diseases, including malignant tumors [20-22], coronary artery disease [23], acute ischemic stroke [24], and preterm premature rupture of the membranes [25]. Moreover, high SII $(\geq 834.89)$ was newly identified as a good risk predictor for discriminating osteoporotic fracture risk in postmenopausal osteoporosis patients [26]. Recently, we also firstly reported that high platelet-to-lymphocyte ratio (PLR) was associated with increased 1 year all-cause mortality in older adults with hip fracture [27]. As far as we know, no studies have investigated the relationship between SII and mortality in older adults with hip fracture. Therefore, the aim of this study was to explore the predictive value of SII in older adults with hip fracture.

\section{Methods}

\section{Study design and participants}

This was a prospective cohort study using a hip fracture database from our orthopaedic center in Deyang city, China. As we previously described [27], patients were included in the database if the following criteria were met: (I) aged over 60 years; (II) diagnosed with hip fracture, not pathological fracture; (III) caused by a low-energy mechanism (defined as a fall from no greater than standing height); (IV) fresh fracture less than 3 weeks. After inclusion, we then entered the demographic details [age at admission (years), sex (male/female)], clinical characteristics [admission date and diagnosis, hip fracture type (femur neck fracture/ intertrochanteric fracture), comorbidities, treatment (surgical/conservative), discharge date and diagnosis)], surgical information [date of surgery, type of surgery (internal fixation/arthroplasty), anaesthesia (general/ spinal), and time to surgery], and laboratory data at admission (routine blood test, liver and kidney function, and electrolyte). In this study, patients with conservative treatment, no one follow-up information, chronic or acute infection within $48 \mathrm{~h}$ of admission, missing values for platelet, neutrophil, lymphocyte counts were excluded. The study was approved by the Institutional Ethics Committee of People's Hospital of Deyang City.

\section{Assessment of SII}

Whole blood samples $(1.0 \mathrm{~mL})$ were routinely obtained from all patients within $24 \mathrm{~h}$ after hospital admission, and blood routine examination was performed immediately by an automatic hematology analyzer (Sysmex XN2000, Kobe, Japan). The SII was calculated from the platelet counts (reference range: $100-300 \times 10^{9} / \mathrm{L}$ ), neutrophil counts (reference range: $4-10 \times 10^{9} / \mathrm{L}$ ), and lymphocyte counts (reference range: 1.1-3.2 $\times 10^{9} / \mathrm{L}$ ), using the following formula: SII = platelet $\times$ neutrophil/ lymphocyte counts as defined previously [28]. The SII was expressed as $\times 10^{9} / \mathrm{L}$.

\section{Follow-up and outcome}

After discharge, all living patients in the hip fracture database were telephonically followed up monthly for the first 3 months, and then every 3 months until the 1 year, and every 6 months thereafter. The follow-up contents included survival status (alive/death), time of death and cause of death. The date of in-hospital death were obtained from electronic medical records. Survival time was calculated from the date of hospital admission to either the date of death from any cause or last follow-up (December 31, 2019), whichever came first. The outcomes were all-cause mortality at 30 days, 1 year and last follow-up.

\section{Assessment of potential confounders}

A number of variables were extracted from the hip fracture database, including demographic and clinical characteristics, and other laboratory data. Time to surgery was calculated as the date of surgery minus hospital admission date. The presence of comorbidity was evaluated using Charlson comorbidity index (CCI) score, which comprises 17 comorbid conditions and assigned a weigh of 1 to 6 points according to its impact on mortality [29]. Based on prior studies, CCI was categorized as none $(\mathrm{CCI}=0)$, low $(\mathrm{CCI}=1)$, or high $(\mathrm{CCI} \geq 2)$ [4]. The reference range of albumin was $3.5-5.5 \mathrm{~g} / \mathrm{dL}$, and no patient exceeded the upper limit. The albumin levels were then classified into hypoalbuminemia (albumin $<3.5 \mathrm{~g} /$ $\mathrm{dL}$ ) and normal albumin (albumin $\geq 3.5 \mathrm{~g} / \mathrm{dL}$ ) [30].

\section{Statistical analysis}

All data received a double check before the analysis, and missing data were identified, including serum albumin $(n=7,2.4 \%)$, time to surgery $(n=5,1.7 \%)$. While the missing data were continuous variables, and the percentages were low, they were supplemented with simple imputations using the median nonmissing value, as described elsewhere [31]. Continous data were expressed as means (standard deviation, SD) or median (interquartile range, IQR) according to the distribution, and examined by independent Student's $t$-test for normally 
distributed variables, and Wilcoxon rank-sum test for non-normally distributed variables. Categorical data were described as frequencies (percentages), and compared by $\chi^{2}$ test.

The median follow-up time was identified as a median observation time of patients who were still alive at last follow-up, and estimated by the reverse Kaplan-Meier method. Univariable Cox proportional hazard models were carried out to estimate the effect of each predictor on 30-day, 1-year and total mortality. Further multivariable Cox analyses were performed to identify the independent risk factors for survival. Proportional hazard assumption was assessed for all variables, using the Kaplan-Meier estimates for the categorical variables and the Schoenfeld's residuals for the countinous variables [32]. Owing to the small number of death, we did not perform multivariable adjustment for 30-day mortality, and other multivariable models were adjusted for the following potential confounders identified in the previous literature [30, 33], including age, sex, time to surgery, CCI score and hypoalbuminemia. In these models, SII value was divided by 100 in order to improve the readability of hazard ratio (HR).
Moreover, subgroup analyses were performed according to age $(<80$ or $\geq 80$ years), sex (male or female), CCI score $(0,1, \geq 2)$ and albumin level $(\geq 3.5 \mathrm{~g} / \mathrm{dL}$ or $<3.5 \mathrm{~g} /$ $\mathrm{dL})$. We also conducted a test for the interaction between SII and each subgroup factors.

All statistical analyses were performed using JMP Pro software (version 13.0.0; SAS Institute Inc., Cary, NC, USA). A two-tailed $p<0.05$ was considered statistically significant.

\section{Results}

\section{Baseline characteristics}

Between January 2014 and December 2018, a total of 920 hip fracture patients treated at our orthopaedic center, and 660 patients have been consecutively included in the hip fracture database. In this study, we excluded those who received conservative treatment $(n=221)$, had no one follow-up information $(n=58)$, chronic or acute infection within $48 \mathrm{~h}$ of admission $(n=56)$, and missing values for platelet, neutrophil, lymphocyte counts $(n=$ 35). Finally, 290 patients undergoing surgery were included in the final analysis (Fig. 1).

The baseline characteristics are presented in Table 1. The mean (SD) age was $77.6(8.6)$ years, and $65.2 \%$ were

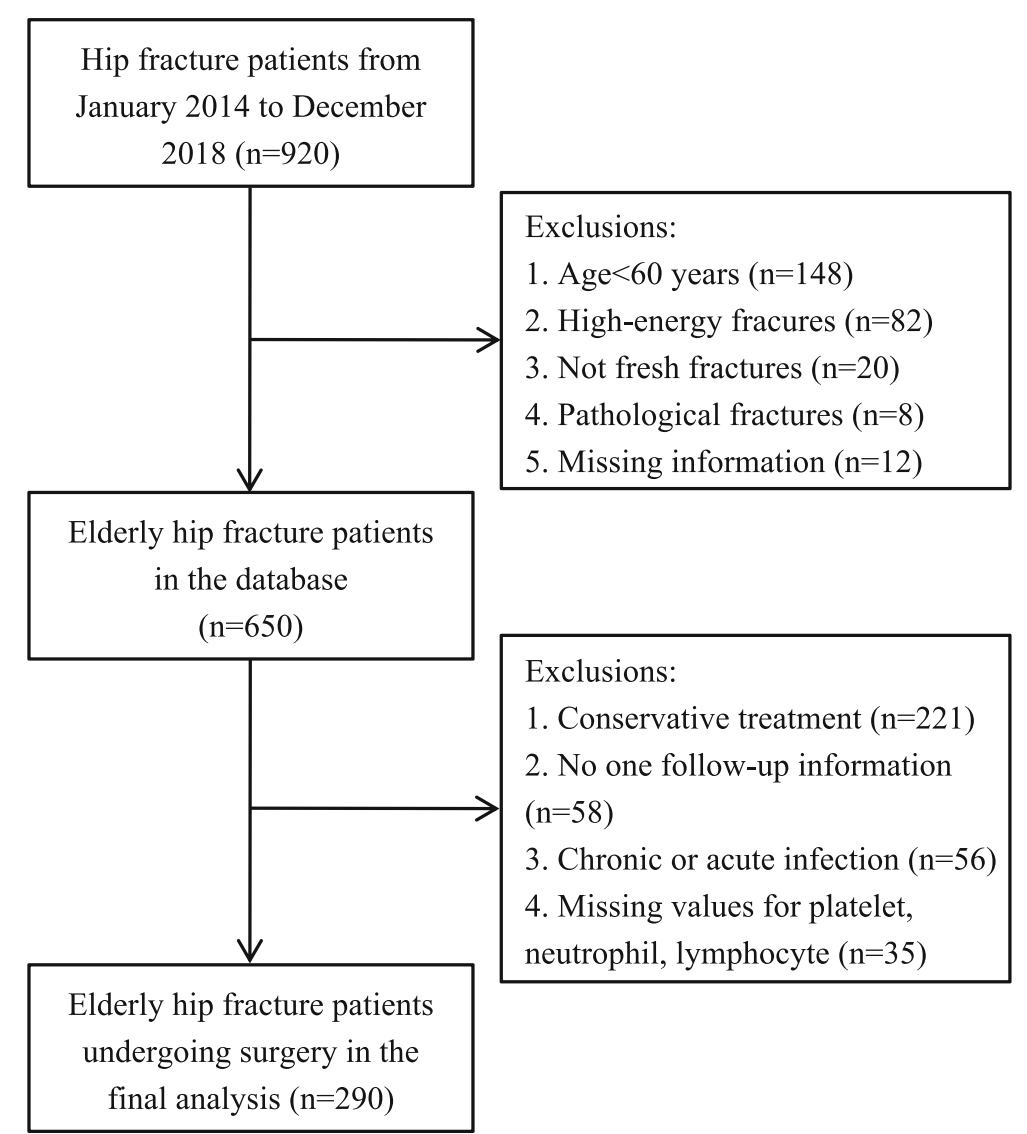

Fig. 1 Flow chart of the study participants 
Table 1 Baseline characteristics

\begin{tabular}{|c|c|}
\hline Characteristics & Total $(N=290)$ \\
\hline Age (years), mean (SD) & $77.6(8.6)$ \\
\hline Female, n (\%) & $189(65.2)$ \\
\hline \multicolumn{2}{|l|}{ CCl score, n (\%) } \\
\hline $\mathrm{CCl}=0$ & $159(54.8)$ \\
\hline $\mathrm{CCl}=1$ & $89(30.7)$ \\
\hline $\mathrm{CCl} \geq 2$ & $42(14.5)$ \\
\hline \multicolumn{2}{|l|}{ Type of hip fracture, n(\%) } \\
\hline Femoral neck & $158(54.5)$ \\
\hline Intertrochanteric & $132(45.5)$ \\
\hline \multicolumn{2}{|l|}{ Type of surgery, n (\%) } \\
\hline Internal fixation & $162(55.9)$ \\
\hline Arthroplasty & $128(44.1)$ \\
\hline Time to surgery (days), median (IQR) & $5.6(4.0-7.5)$ \\
\hline Platelet $\left(\times 10^{9} / \mathrm{L}\right)$, median (IQR) & 139.0(102.0-177.3) \\
\hline Neutrophil $\left(\times 10^{9} / \mathrm{L}\right)$, median (IQR) & $5.6(4.4-7.4)$ \\
\hline Lymphocyte $\left(\times 10^{9} / \mathrm{L}\right)$, median (IQR) & $1.0(0.8-1.3)$ \\
\hline SII (×10\%/L), median (IQR) & 759.4(519.0-1128.7) \\
\hline Albumin (g/dL), mean (SD) & $3.8(0.4)$ \\
\hline Hypoalbuminemia, n(\%) & 75 (25.9) \\
\hline
\end{tabular}

Continous data were expressed as mean (SD) or median (IQR) according to the distribution, and categorical data were described as frequencies (percentages) Abbreviation: SD Standard deviation, $\mathrm{CCl}$ Charlson comorbidity index, IQR Interquartile range, SII Systemic immune-inflammation index female. According to the CCI score, 159 (54.8\%) patients were classified as none comorbidity, $89(30.7 \%)$ patients as low comorbidity, and $42(14.5 \%)$ patients as high comorbidity. The most common type of hip fracture was femoral neck (54.5\%), and more than half (55.9\%) underwent internal fixation surgery, and the median (IQR) time to surgery was $5.6(4.0-7.5)$ days, and $25.9 \%$ were hypoalbuminemia. Moreover, the median (IQR) SII was $759.4(519.0-1128.7) \times 10^{9} / \mathrm{L}$.

\section{Mortality}

After a median (IQR) follow-up time of 33.4 (22.8-48.9) months, 54 patients (18.6\%) died, of which 3 deaths $(1.0 \%)$ occurred in hospital. Overall, the mortality rates at 30 days and 1 year were $4.5 \%(n=13)$ and $9.0 \%(n=$ 26), respectively. Compared with patients still alive, deceased patients had a significantly higher SII value at 30 days, 1 year and last follow-up (Fig. 2).

\section{Risk factors for predicting mortality}

As shown in Table 2, univariable analysis showed that increasing age, male, high CCI score, time delay for surgery, hypoalbuminemia, and SII were associated with increased 30-day, 1-year and total mortality. Both types of hip fracture and surgery were not found to be risk factors. After adjusting for other covariates (Table 3), each increase of 100 units of SII was associated with a $8 \%$ increased hazard of death at 1-year follow-up $(\mathrm{HR}=1.08$, 95\% CI: 1.01-1.17, $p=0.033)$, and 9\% increased hazard of death at last follow-up (HR $=1.09,95 \% \mathrm{CI}: 1.03-1.15$, $p=0.003)$. Moreover, male, high CCI score, and hypoalbuminemia were significantly associated with 1-year
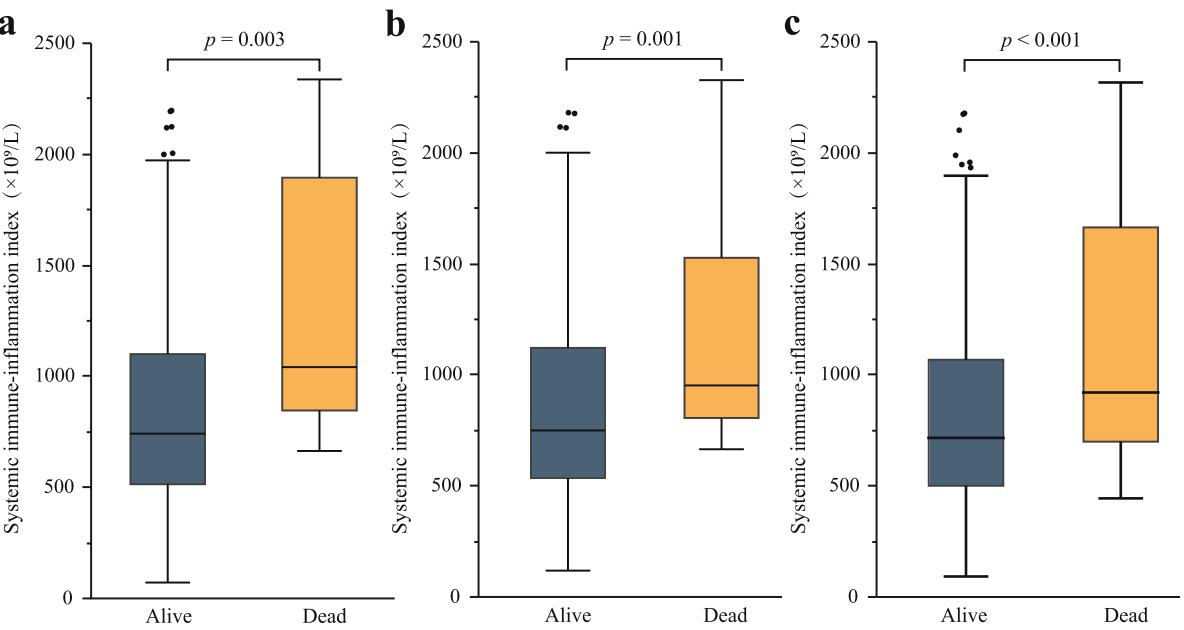

Fig. 2 Box-plots comparing systemic immune-inflammation index (SII) among alive and dead patients at different times. a 30 days; b 1 year; c last time of follow-up. Blue box plots represent alive patients, whereas yellow box plots represent dead patients. The horizontal lines within the boxes represent the median; the boxes represent the interquartile range; the ends of the whiskers represent the minimum and maximum values, excluding the outliers; dots above and below the box plots represent outliers. Differences between groups were analyzed by Wilcoxon rank-sum test 
Table 2 Univariable Cox regression analysis for the risk factors associated with 30-day, 6-month and 1-year mortality

\begin{tabular}{|c|c|c|c|c|c|c|}
\hline \multirow[t]{2}{*}{ Variables } & \multicolumn{2}{|l|}{ 30-day mortality } & \multicolumn{2}{|l|}{ 1-year mortality } & \multicolumn{2}{|l|}{ Total mortality } \\
\hline & $\mathrm{HR}(95 \% \mathrm{Cl})$ & $p$ value & HR $(95 \% \mathrm{Cl})$ & $p$ value & $\mathrm{HR}(95 \% \mathrm{Cl})$ & $p$ value \\
\hline Age (per 1 year increase) & $1.12(1.04-1.21)$ & 0.002 & $1.07(1.02-1.12)$ & 0.008 & $1.08(1.04-1.12)$ & $<0.001$ \\
\hline Sex (male vs. female) & $4.40(1.43-16.24)$ & 0.009 & $3.81(1.74-8.94)$ & 0.001 & $2.11(1.24-3.62)$ & 0.007 \\
\hline $\mathrm{CCl}=0$ & 1.00 (Reference) & - & 1.00 (Reference) & - & 1.00 (Reference) & - \\
\hline $\mathrm{CCl}=1$ & $1.79(0.33-9.69)$ & 0.478 & $1.82(0.62-5.32)$ & 0.266 & $1.35(0.67-2.65)$ & 0.396 \\
\hline $\mathrm{CCl} \geq 2$ & $9.66(2.68-44.83)$ & 0.001 & $7.53(3.03-20.24)$ & $<0.001$ & $5.03(2.69-9.42)$ & $<0.001$ \\
\hline Fracture type (intertrochanteric vs. neck) & $1.97(0.66-6.52)$ & 0.226 & $1.23(0.57-2.68)$ & 0.595 & $1.62(0.94-2.80)$ & 0.083 \\
\hline Surgery type (fixation vs. arthroplasty) & $1.81(0.59-6.70)$ & 0.306 & $1.10(0.51-2.45)$ & 0.816 & $1.15(0.67-1.99)$ & 0.604 \\
\hline Time to surgery (per 1 day increase) & $1.10(0.83-1.30)$ & 0.411 & $1.10(1.01-1.17)$ & 0.023 & $1.14(1.08-1.19)$ & $<0.001$ \\
\hline Albumin $(<3.5 \mathrm{~g} / \mathrm{dL}$ vs. $\geq 3.5 \mathrm{~g} / \mathrm{dL})$ & $4.77(1.59-15.79)$ & 0.006 & $4.27(1.97-9.53)$ & $<0.001$ & $2.52(1.46-4.32)$ & 0.001 \\
\hline SII (per 100 units) & $1.16(1.05-1.28)$ & 0.003 & $1.11(1.04-1.19)$ & 0.004 & $1.12(1.07-1.18)$ & $<0.001$ \\
\hline
\end{tabular}

Abbreviation: HR Hazard ratio, Cl Confidence interval, CCl Charlson comorbidity index, SIl Systemic immune-inflammation index

mortality, and increasing age, high CCI score, time delay for surgery, and hypoalbuminemia were significantly associated with total mortality.

\section{Subgroup analysis}

To further verify whether the predictive role of SII was consistent among different clinical situations, we performed subgroup analyses (Table 4). Consistent with the overall results, SII was also significantly associated with poor 1-year and total mortality. Moreover, there was no significant interaction between all the subgroup factors.

\section{Discussion}

In this study, the overall mortality at 30 days, 1 year and total mortality at last follow-up were 4.5, 9.0 and 18.6\%, which were lower than that in other countries $[5,6]$. A recent systematic analysis calculated the 1-year mortality rate after hip fracture in mainland China, and the estimated mortality was $13.96 \%$ (95\% CI: $12.26-15.86 \%$ ) [34]. A study from Singapore also showed that the mortality was lower, and the rate was $1.8 \%$ at 30 days, and
$13.3 \%$ at 2 years [3]. In the present study, many of those patients $(33.5 \%)$ were treated conservatively and had a higher mortality rate, but we excluded these patients in the final analysis due to different clinical features. This may be the reason for the lower mortality rates in our study.

Recently, the relationship between inflammation and prognosis has attracted more attention in older adults [35, 36]. Bermejo-Bescós et al. [14] found that peripheral IL-6 level was significantly associated with a higher risk of 1-year mortality after hip fracture in patients over 80 years. Several biochemical markers of inflammation, such as levels of CRP, the soluble urokinase plasminogen activating receptor (suPAR) and ferritin, were found to be associated with 30-day mortality after hip fracture [15]. Hip fracture also led to significant systemic inflammation and acute lung injury in rat models, and the older rats suffered a more remarkable acute lung injury after hip fracture than the younger rats [37]. Although other study has found no such relationship between high inflammatory markers and 2-year mortality in hip fracture patients [38], most studies suggest that systemic

Table 3 Multivariable Cox regression analysis for the risk factors associated with 1-year and total mortality

\begin{tabular}{|c|c|c|c|c|}
\hline \multirow[t]{2}{*}{ Variables } & \multicolumn{2}{|l|}{ 1-year mortality } & \multicolumn{2}{|l|}{ Total mortality } \\
\hline & HR $(95 \% \mathrm{Cl})$ & $p$ value & HR $(95 \% \mathrm{Cl})$ & $p$ value \\
\hline Age (per 1 year increase) & $1.04(0.98-1.10)$ & 0.173 & $1.06(1.02-1.10)$ & 0.003 \\
\hline Sex (male vs. female) & $2.82(1.26-6.71)$ & 0.011 & $1.72(0.98-3.01)$ & 0.056 \\
\hline $\mathrm{CCl}=0$ & 1.00 (Reference) & - & 1.00 (reference) & - \\
\hline $\mathrm{CCl}=1$ & $1.35(0.45-4.02)$ & 0.585 & $1.00(0.49-1.98)$ & 0.991 \\
\hline $\mathrm{CCl} \geq 2$ & $5.04(1.84-14.51)$ & 0.002 & $2.97(1.45-5.98)$ & 0.003 \\
\hline Time to surgery (per 1 day increase) & $1.02(0.99-1.09)$ & 0.639 & $1.07(1.02-1.13)$ & 0.016 \\
\hline Albumin $(<3.5 \mathrm{~g} / \mathrm{dL}$ vs. $\geq 3.5 \mathrm{~g} / \mathrm{dL})$ & $2.93(1.29-6.88)$ & 0.010 & $1.83(1.03-3.22)$ & 0.040 \\
\hline SII (per 100 units increase) ${ }^{b}$ & $1.08(1.01-1.17)$ & 0.033 & $1.09(1.03-1.15)$ & 0.003 \\
\hline
\end{tabular}

Adjusted for age, sex, $\mathrm{CCl}$ score, time to surgery and albumin level

Abbreviation: HR Hazard ratio, Cl Confidence interval, CCI Charlson comorbidity index, SIl Systemic immune-inflammation index 
Table 4 Subgroup analysis by age, sex, CCI score and albumin for 1-year and total mortality

\begin{tabular}{|c|c|c|c|c|c|c|}
\hline \multirow[t]{2}{*}{ Subgroups } & \multicolumn{3}{|l|}{ 1-year mortality } & \multicolumn{3}{|l|}{ Total mortality } \\
\hline & $\mathrm{HR}(95 \% \mathrm{Cl})$ & $p$ value & Interaction $p$ value & HR (95\% CI) & $p$ value & Interaction $p$ value \\
\hline Age & & & 0.693 & & & 0.632 \\
\hline$<80$ years & $1.10(0.95-1.26)$ & 0.171 & & $1.09(0.99-1.20)$ & 0.093 & \\
\hline$\geq 80$ years & $1.10(1.00-1.21)$ & 0.041 & & $1.10(1.03-1.18)$ & 0.005 & \\
\hline Sex & & & 0.357 & & & 0.833 \\
\hline Male & $1.11(1.01-1.21)$ & 0.030 & & $1.08(1.01-1.16)$ & 0.031 & \\
\hline Female & $1.04(0.89-1.19)$ & 0.595 & & $1.10(1.01-1.19)$ & 0.011 & \\
\hline CCl score & & & 0.686 & & & 0.241 \\
\hline $\mathrm{CCl}=0$ & $1.06(0.91-1.22)$ & 0.425 & & $1.13(1.03-1.23)$ & 0.009 & \\
\hline $\mathrm{CCl}=1$ & $1.13(0.99-1.29)$ & 0.073 & & $1.12(1.01-1.23)$ & 0.027 & \\
\hline $\mathrm{CCl} \geq 2$ & $1.08(0.95-1.23)$ & 0.247 & & $1.04(0.94-1.16)$ & 0.413 & \\
\hline Albumin & & & 0.639 & & & 0.710 \\
\hline$\geq 3.5 \mathrm{~g} / \mathrm{dL}$ & $1.12(1.00-1.24)$ & 0.034 & & 1.09 (1.02-1.18) & 0.019 & \\
\hline$<3.5 \mathrm{~g} / \mathrm{dL}$ & $1.11(1.00-1.22)$ & 0.051 & & $1.08(1.00-1.17)$ & 0.063 & \\
\hline
\end{tabular}

Adjusted for age, sex, $\mathrm{CCl}$ score, time to surgery and albumin level

Abbreviation: $\mathrm{HR}$ Hazard ratio, $\mathrm{Cl}$ Confidence interval, $\mathrm{CCl}$ Charlson comorbidity index

inflammation may be related to the poor survival of hip fracture.

The SII is an objective marker to reflect the systemic inflammation, and easy to calculate by the platelet $\times$ neutrophil/lymphocyte counts formula. In older adults with hip fracture, more than half of the patients (62.6\%) had low lymphocyte counts [39]. A recent meta-analysis reported that low total lymphocyte counts were significantly associated with higher total mortality $(\mathrm{HR}=1.67,95 \% \mathrm{CI}: 1.28-2.18)$ [40]. Although there is no direct evidence that increased neutrophil counts are related to poor prognosis, elevated neutrophil-to-lymphocyte ratio was found to be an independent risk factor for postoperative myocardial injury, in-hospital death and 1-year mortality after hip fracture surgery $[18,19]$. On the other hand, high platelet counts were considered to be a risk factor for developing a postoperative pressure ulcer after hip fracture surgery [41], and elevated PLR was found to be associated with increased all-cause mortality, especially in the older adults [42]. Recently, we also reported that high PLR $(\geq 189)$ was associated with increased 1-year all-cause mortality in older adults with hip fracture [27]. Therefore, we speculated that elevated SII level by raising platelet, neutrophil counts and/or lowering lymphocyte counts may be possible to predict poor prognosis in older adults with hip fracture.

As expected, we first observed that dead patients had a significantly higher SII value in comparison with survivors. Moreover, multivariable analysis confirmed that SII was significantly associated with 1 -year mortality $(\mathrm{HR}=1.08$ per 100 units, 95\% CI:
1.01-1.17), and total mortality at last follow-up $(\mathrm{HR}=1.09$ per 100 units, 95\% CI: 1.03-1.15). To further verify whether the predictive role of SII was consistent among different clinical situations, subgroup analyses also revealed that SII remained as an independent risk factor for survival in older adults with hip fracture, and there was no significant interaction.

Furthermore, our study showed that male, high CCI score, and hypoalbuminemia were significantly associated with 1-year mortality, and increasing age, high CCI score, time delay for surgery, and hypoalbuminemia were significantly associated with total mortality. These risk factors have been proven in other studies [3-5, 30, 33]. In this study, increasing age and time delay for surgery lost significance as independent factors for 1-year mortality. This may be due to a small number of death within 1-year follow-up.

However, our study also had several limitations. First, the sample size was small, this reduced the statistical power of the study. Meanwhile, the small number of deaths limited the ability to interpret our data on short-term mortality. Further studies with larger sample sizes are required to confirm our findings. Second, we did not obtain some variables related to survival, such as body mass index [43], time from fracture to hospital admission [44]. These unadjusted potential confounding factors may influence the results of this study. Third, only laboratory data at admission were entered in the hip fracture database, this also limited us to explore the relationship between SII at other time points and survival after hip fracture. 


\section{Conclusions}

Our findings demonstrate that SII is significantly associated with poor all-cause mortality in older adults with hip fracture undergoing surgery, and it may be a good index to predict the prognosis. Because SII is a simple and economical biomarker, it can be easily performed in usual clinical practice.

\section{Abbreviations \\ SII: Systemic immune-inflammation index; HR: Hazard ratio; SD: Standard deviation; IQR: Interquartile range; NHFS: Nottingham Hip Fracture Score; POSSUM: Physiologic and Operative Severity Score for the enUmeration of Mortality and Morbidity; AHFS: Almelo Hip Fracture Score; CCl: Charlson Comorbidity Index; IL-6: Interleukin-6; CRP: C-reactive protein; PNI: Prognostic nutritional index ratio; NLR: Neutrophil-to-lymphocyte ratio; Cl: Confidence interval; suPAR: The soluble urokinase plasminogen activating receptor; PLR: Platelet-to-lymphocyte ratio}

\section{Acknowledgements}

We thank several nurses from the Department of Orthopedics in People's Hospital of Deyang City, for the help with the data inspection.

\section{Authors' contributions}

YHL designed the study and revised the manuscript. ZCW and WJ analyzed the data and wrote the manuscript. XC, HW and LY collected the data. All authors read and approved the final version of the manuscript.

\section{Funding}

This study was supported by Deyang Science and Technology Bureau (grant number: 2019SZ125). The sponsor had no role in the design, data collection, analysis, or preparation of the manuscript.

\section{Availability of data and materials}

The datasets used and /or analyzed during the current study are available from the corresponding author on reasonable request.

\section{Declarations}

\section{Ethics approval and consent to participate}

The study protocol was approved by the Institutional Ethics Committee of People's Hospital of Deyang City (number: 2020-04-033). The participants were informed about the study and signed the written informed consent.

\section{Consent for publication}

Not applicable.

\section{Competing interests}

The authors declare that they have no competing interests.

Received: 30 June 2020 Accepted: 22 February 2021

Published online: 04 March 2021

\section{References}

1. Johnell O, Kanis JA. An estimate of the worldwide prevalence and disability associated with osteoporotic fractures. Osteoporos Int. 2006;17(12):1726-33.

2. Gullberg B, Johnell O, Kanis JA. World-wide projections for hip fracture. Osteoporos Int. 1997;7(5):407-13.

3. Cher EWL, Allen JC, Howe TS, Koh JSB. Comorbidity as the dominant predictor of mortality after hip fracture surgeries. Osteoporos Int. 2019; 30(12):2477-83.

4. Beaupre LA, Khong H, Smith C, Kang S, Evens L, Jaiswal PK, Powell JN. The impact of time to surgery after hip fracture on mortality at 30- and 90-days: does a single benchmark apply to all? Injury. 2019;50(4):950-5.

5. Leer-Salvesen S, Engesæter LB, Dybvik E, Furnes O, Kristensen TB, Gjertsen JE. Does time from fracture to surgery affect mortality and intraoperative medical complications for hip fracture patients? An observational study of 73557 patients reported to the Norwegian Hip Fracture Register. Bone Joint J. 2019;9:1129-37.
6. Yombi JC, Putineanu DC, Cornu O, Lavand'homme P, Cornette P, Castanares-Zapatero D. Low haemoglobin at admission is associated with mortality after hip fractures in elderly patients. Bone Joint J. 2019;9:1122-8.

7. Yagi T, Oshita Y, Okano I, Kuroda T, Ishikawa K, Nagai T, Inagaki K Controlling nutritional status score predicts postoperative complications after hip fracture surgery. BMC Geriatr. 2020;20(1):243.

8. Rushton PR, Reed MR, Pratt RK. Independent validation of the Nottingham hip fracture score and identification of regional variation in patient risk within England. Bone Joint J. 2015;1:100-3.

9. Doherty WJ, Stubbs TA, Chaplin A, Reed MR, Sayer AA, Witham MD, Sorial AK. Prediction of postoperative outcomes following hip fracture surgery: independent validation and recalibration of the Nottingham hip fracture score. J Am Med Dir Assoc. 2020. https://doi.org/10.1016/j.jamda.2020.07. 013.

10. Johns WL, Strong B, Kates S, Patel NK. POSSUM and P-POSSUM scoring in hip fracture mortalities. Geriatr Orthop Surg Rehabil. 2020;11: 2151459320931674

11. Jonsson MH, Bentzer P, Turkiewicz A, Hommel A. Accuracy of the Physiological and Operative Severity Score for the enUmeration of Mortality and morbidity score and the Nottingham risk score in hip fracture patients in Sweden - A prospective observational study. Acta Anaesthesiol Scand. 2018. https://doi.org/10.1111/aas.13131.

12. Nijmeijer WS, Folbert EC, Vermeer M, Slaets JP, Hegeman JH. Prediction of early mortality following hip fracture surgery in frail elderly: the Almelo Hip Fracture Score (AHFS). Injury. 2016;47(10):2138-43.

13. Karres J, Heesakkers NA, Ultee JM, Vrouenraets BC. Predicting 30-day mortality following hip fracture surgery: evaluation of six risk prediction models. Injury. 2015;46(2):371-7.

14. Bermejo-Bescós P, Martín-Aragón S, Cruz-Jentoft AJ, Merello de Miguel A, Vaquero-Pinto MN. Peripheral IL-6 levels but not sarcopenia are predictive of 1-year mortality after hip fracture in older patients. J Gerontol A Biol Sci Med Sci. 2020;75(10):e130-7.

15. Norring-Agerskov D, Bathum L, Pedersen OB, Abrahamsen B, Lauritzen JB, Jørgensen NR. Biochemical markers of inflammation are associated with increased mortality in hip fracture patients: the Bispebjerg Hip Fracture Biobank. Aging Clin Exp Res. 2019;31(12):1727-34.

16. Xing H, Xiang D, Li Y, Ji X, Xie G. Preoperative prognostic nutritional index predicts postoperative delirium in elderly patients after hip fracture surgery. Psychogeriatrics. 2020;20(4):487-94.

17. Ren H, Wu L, Hu W, Ye X, Yu B. Prognostic value of the c-reactive protein/ prognostic nutritional index ratio after hip fracture surgery in the elderly population. Oncotarget. 2017;8(37):61365-72.

18. Fisher A, Srikusalanukul W, Fisher L, Smith P. The neutrophil to lymphocyte ratio on admission and short-term outcomes in orthogeriatric patients. Int $J$ Med Sci. 2016;13(8):588-602

19. Forget $P$, Moreau N, Engel H, Cornu O, Boland B, De Kock M, Yombi JC. The neutrophil-to-lymphocyte ratio (NLR) after surgery for hip fracture (HF). Arch Gerontol Geriatr. 2015;60(2):366-71

20. He H, Guo W, Song P, Liu L, Zhang G, Wang Y, Qiu B, Tan F, Xue Q, Gao S. Preoperative systemic immune-inflammation index and prognostic nutritional index predict prognosis of patients with pulmonary neuroendocrine tumors after surgical resection. Ann Transl Med. 2020;8(10):630.

21. Hu X, Shao YX, Yang ZQ, Dou WC, Xiong SC, Li X. Preoperative systemic immune-inflammation index predicts prognosis of patients with nonmetastatic renal cell carcinoma: a propensity score-matched analysis. Cancer Cell Int. 2020;20:222

22. Hua X, Long ZQ, Zhang YL, Wen W, Guo L, Xia W, Zhang WW, Lin HX Prognostic value of preoperative systemic immune-inflammation index in breast cancer: a propensity score-matching study. Front Oncol. 2020;10:580.

23. Yang YL, Wu CH, Hsu PF, Chen SC, Huang SS, Chan WL, Lin SJ, Chou CY, Chen JW, Pan JP. Systemic immune-inflammation index (SII) predicted clinical outcome in patients with coronary artery disease. Eur J Clin Invest. 2020;50(5):e13230

24. Hou D, Wang C, Luo Y, Ye X, Han X, Feng Y, Zhong P, Wu D. Systemic immune-inflammation index (SII) but not platelet-albumin-bilirubin (PALBI) grade is associated with severity of acute ischemic stroke (AIS). Int Neurosci. 2020. https://doi.org/10.1080/00207454.2020.1784166.

25. Tanacan A, Uyanik E, Unal C, Beksac MS. A cut-off value for systemic immune-inflammation index in the prediction of adverse neonatal outcomes in preterm premature rupture of the membranes.J Obstet Gynaecol Res. 2020;46(8):1333-41. 
26. Fang $H$, Zhang H, Wang Z, Zhou Z, Li Y, Lu L. Systemic immuneinflammation index acts as a novel diagnostic biomarker for postmenopausal osteoporosis and could predict the risk of osteoporotic fracture. J Clin Lab Anal. 2020;34(1):e23016.

27. Wang ZC, Wang H, Yang L, Jiang W, Chen X, Liu YH. High platelet-tolymphocyte ratio predicts poor survival of elderly patients with hip fracture. Int Orthop. 2021;45(1):13-21.

28. Hu B, Yang XR, Xu Y, Sun YF, Sun C, Guo W, Zhang X, Wang WM, Qiu SJ, Zhou J, Fan J. Systemic immune-inflammation index predicts prognosis of patients after curative resection for hepatocellular carcinoma. Clin Cancer Res. 2014;20(23):6212-22.

29. Charlson M, Szatrowski TP, Peterson J, Gold J. Validation of a combined comorbidity index. J Clin Epidemiol. 1994;47(11):1245-51.

30. Bohl DD, Shen MR, Hannon CP, Fillingham YA, Darrith B, Della Valle CJ. Serum albumin predicts survival and postoperative course following surgery for geriatric hip fracture. J Bone Joint Surg Am. 2017;99(24):2110-8.

31. Chen Z, Hu H, Chen M, Luo X, Yao W, Liang Q, Yang F, Wang X. Association of Triglyceride to high-density lipoprotein cholesterol ratio and incident of diabetes mellitus: a secondary retrospective analysis based on a Chinese cohort study. Lipids Health Dis. 2020;19(1):33.

32. Fest J, Ruiter R, Mulder M, Groot Koerkamp B, Ikram MA, Stricker BH, van Eijck CHJ. The systemic immune-inflammation index is associated with an increased risk of incident cancer-a population-based cohort study. Int J Cancer. 2020;146(3):692-8.

33. Yong EL, Ganesan G, Kramer MS, Howe TS, Koh JSB, Thu WP, Logan S, Cauley JA, Tan KB. Risk factors and trends associated with mortality among adults with hip fracture in Singapore. JAMA Netw Open. 2020;3(2):e1919706.

34. Cui Z, Feng H, Meng X, Zhuang S, Liu Z, Ye K, Sun C, Xing Y, Zhou F, Tian Y. Age-specific 1-year mortality rates after hip fracture based on the populations in mainland China between the years 2000 and 2018: a systematic analysis. Arch Osteoporos. 2019;14(1):55.

35. Wang R, Wen X, Huang C, Liang Y, Mo Y, Xue L. Association between inflammation-based prognostic scores and in-hospital outcomes in elderly patients with acute myocardial infarction. Clin Interv Aging. 2019;14:1199-206.

36. Ferrucci L, Fabbri E. Inflammageing: chronic inflammation in ageing, cardiovascular disease, and frailty. Nat Rev Cardiol. 2018;15(9):505-22.

37. Gan L, Sun T, Li B, Tian J, Zhang J, Chen X, Zhong J, Yang X, Li Q. Serum miR-146a and miR-150 as potential new biomarkers for hip fracture-induced acute lung injury. Mediators Inflamm. 2018;2018:8101359.

38. Saribal D, Hocaoglu-Emre FS, Erdogan S, Bahtiyar N, Caglar Okur S, Mert M. Inflammatory cytokines IL-6 and TNF- $a$ in patients with hip fracture. Osteoporos Int. 2019;30(5):1025-31.

39. Wilson JM, Boissonneault AR, Schwartz AM, Staley CA, Schenker ML. Frailty and malnutrition are associated with inpatient postoperative complications and mortality in hip fracture patients. J Orthop Trauma. 2019;33(3):143-8.

40. Li S, Zhang J, Zheng H, Wang X, Liu Z, Sun T. Prognostic role of serum albumin, total lymphocyte count, and mini nutritional assessment on outcomes after geriatric hip fracture surgery: a meta-analysis and systematic review. J Arthroplasty. 2019;34(6):1287-96.

41. Galivanche AR, Kebaish KJ, Adrados M, Ottesen TD, Varthi AG, Rubin LE, Grauer JN. Postoperative pressure ulcers after geriatric hip fracture surgery are predicted by defined preoperative comorbidities and postoperative complications. J Am Acad Orthop Surg. 2020;28(8):342-51.

42. Mathur K, Kurbanova N, Qayyum R. Platelet-lymphocyte ratio (PLR) and allcause mortality in general population: insights from national health and nutrition education survey. Platelets. 2019;30(8):1036-41.

43. Modig K, Erdefelt A, Mellner C, Cederholm T, Talbäck M, Hedström M. "Obesity paradox" holds true for patients with hip fracture: a registry-based cohort study. J Bone Joint Surg Am. 2019;101(10):888-95.

44. He W, You YY, Sun K, Xie C, Ming Y, Yu LN, Zhang FJ, Yan M. Admission delay is associated with worse surgical outcomes for elderly hip fracture patients: a retrospective observational study. World J Emerg Med. 2020; 11(1):27-32.

\section{Publisher's Note}

Springer Nature remains neutral with regard to jurisdictional claims in published maps and institutional affiliations.

\section{Ready to submit your research? Choose BMC and benefit from}

- fast, convenient online submission

- thorough peer review by experienced researchers in your field

- rapid publication on acceptance

- support for research data, including large and complex data types

- gold Open Access which fosters wider collaboration and increased citations

- maximum visibility for your research: over $100 \mathrm{M}$ website views per year

At BMC, research is always in progress.

Learn more biomedcentral.com/submissions 